\title{
A PREDICTION MODEL FOR CONSUMER BEHAVIOR REGARDING PRODUCT SAFETY
}

\author{
Jerry L. Purswel1, Ph.D. \\ Robert E. Schlegel, Ph.D. \\ Sashi K. Kejriwal \\ School of Industrial Engineering \\ University of Oklahoma \\ Norman, Oklahoma $73 \varnothing 19$
}

\begin{abstract}
The objective of this study was the development of a model to predict whether a consumer would use a product safely as a function of sixteen different individual variables. Subjects were presented with four consumer products to use in an experimental setting where the true purpose of the study was concealed. Discriminant analysis was used to develop a prediction model to classify subjects into categories of safe or unsafe behavior. Prediction accuracy ranged from 68-86 percent for different types of behavior. The research illustrated which variables are important in determining whether a product will be used safely and has implications for product design, warnings, instructions for use and training.
\end{abstract}

\section{INTRODUCTION}

Anyone familar with the field of product liability litigation is aware of the problems of predicting how the user of a product will behave if presented with a situation where they must choose to take some specific action to use the product safely. In an effort to understand how different personal variables affect the behavior of a user when faced with a choice of safe or unsafe behavior, this study was undertaken.

Schwartz et al. (1978) studied the impact of objectively predetermined hazard information on consumer buying decisions, concluding that such information does have a significant impact on the decision to buy a product. Dorris and Tabrizi (1978) found little correlation between the perception of hazardousness of certain products and the hazard index of the Consumer Products Safety Commission. Slovic et al. (198ø) found that safety experts could make good judgements about how hazardous a product was to use, while lay subjects were not able to make such judgements very well. Godfrey et al. (1983) found that the more hazardous a product is perceived to be, the more likely the user is to look for a warning label. Familiarity with a product caused it to be rated as less hazardous. Wright (1982) found that people reported they were less likely to read instructions on products used frequently. Dorris and Purswell (1977) found that none of $1 \varnothing \emptyset$ subjects read the warning label before using a hammer, thus suggesting that familiarity in using a product is related to the perceived hazard.

\section{METHODOLOGY}

\section{Experimental Variables}

If one compiles a candidate list of personal variables which could influence the safety behavior of a person when asked to use a product, there are a large number of possible candidates. Foremost on such a list is some measure of risk-taking by the person. There have been surprisingly few attempts to develop a useful measure of risk-taking propensity based on some type of survey instrument. Measures of risk-taking behavior were therefore chosen as experimental variables to be evaluated. These included the following:

1. Percentage of time that the subject wore seatbelts while driving in town, and on the highway.

2. Use of a life-jacket or not while boating on a lake.

3. Crossing the street while the "Don't Walk" is displayed.

4. Score on a special questionnaire instrument developed for this research.

The special questionnaire was developed and tested for subject pools of 15-2Ø subjects in a stepwise process, refining the questionnaire at each step until the mean score was approximateley the mid point of the scale used for a random group of subjects. The questionnaixe was based on a five point scale from safe to very dangerous, covering the subject's attitudes toward areas such as nuclear power, household 
products, sports activities, work place hazards, etc.

Other variables evaluated as predictors of safety behavior were as follows:

1. Age of subject in years

2. Sex of subject

3. Hazard rating of the product by the subject

4. Familiarity of the subject with the product

5. Recency of use of the product

6. Injury experience with the product

7. Score from the Adventure-seeking scale in the Zuckerman test

8. Score from the Boredom-susceptibility scale in the Zuckerman test

9. Score from the Disinhibition scale in the Zuckerman test

10. Score from the Experience-seeking scale in the Zuckerman test

11. Total score from the Zuckerman test.

\section{Experimental Design}

The multivariate statistical method of analysis selected was discriminant analysis, which involves deriving the linear combination of two or more independent variables which will best discriminate between pre-defined groups, i.e.. subjects who behaved safely and those who behaved unsafely when presented with the experimental task. The research question therefore was the determination of those variables having the best utility to predict safe or unsafe behavior from among the candidate set proposed.

\section{Experimental Task}

A group of products was selected to present a range of responses across the experimental variables chosen for study. A chemical drain opener and an electrical carving knife were chosen because of the likely familiarity of most subjects with these products. A sabre-saw was chosen because it was expected to be less familiar to most of the subjects than the first two items. Finally, a router was chosen for study because it was expected that it would be the least familiar to most of the subjects.

Because of the need to protect the subjects from injury, the type of tasks selected for evaluating safety behavior had to be restricted. Also, it was necessary to conceal the real purpose of the study from the subjects in order to obtain as true a behavioral response as possible. The subjects were asked to evaluate certain "ergonomic" features ofthe tools such as the size of the handle, the weight, or the balance. The "cleaning power" of the drain opener was to be evaluated.

For the drain opener, the safety behavior evaluated was whether the person read the warning label before starting to use the product to open a drain in a sink located in the experimental area. The safety behavior evaluated for the sabre-saw was whether the user unplugged the power cord while changing the blade, which they were asked to do at the start of the task. The instruction booklet with this instruction was placed next to the saw. Similiarly, the label on the electric knife warned users to unplug the knife before inserting the blades. The instructions for the router warned against eye hazards from wooden chips thrown during operation, and goggles were placed beside the router.

Subjects

A total of $5 \emptyset$ subjects participated in this research. Subjects were obtained from the employee and student population of the University of oklahoma, and from adults in a church-affiliated fitness and recreational center in Norman, oklahoma. The age of the subjects age ranged from 21 to $8 \varnothing$ years, with 25 in the 21-3ø group, 14 in the 31-5Ø group, and 11 in the 51-8Ø group. There were 25 males and 25 females. Occupations included students, secretaries, nurses, medical doctors, carpenters, technicians, engineers, lawyers and housewives.

\section{Procedure}

All subjects were told that the purpose of the experiment was to determine preferences in product design. They were assured that all their responses would be confidential. Each subject was asked to use each product to perform a specific task as described earlier. The experimenter was prepared to interrupt any subject if there was danger of injury, and point out the safe way of using the product. This was done in such a way that the purpose of the experiment was concealed until all products had been used.

After the products had been used, each subject was was asked to complete the risk-assessment questionnaire and the Zuckerman tests. The experimenter then obtained the remainder of the 
information for the other experimental variables.

of the sixteen independent variables, ten were continuously scaled, and six were discrete. The discrete variables were converted to rank order as follows:

1. $\operatorname{male}=1$; female=2

2. product use: once/week $=5$; once/month $=4$; once $/ 3$ months $=3$; once $/ 6$ months $=2$; once/year or less $=1$

3. recency of use: last week $=5$; within the last 3 months=4; 6 months ago=3;

1 year ago $=2 ; 1-5$ years ago $=1$

4. injury experience: yes $=1 ;$ no= $\varnothing$

5. wears life jacket: yes $=1 ;$ no=ø

6. crosses at pedestrian crossing: yes $=\varnothing ; n o=1$

\section{RESULTS}

The behavior of the subjects when presented with the experimental situation was recorded using one of the following five categories:

1. Subject did not look for any instructions or warnings before using the product in an unsafe manner.

2. Subject viewed instructions or warnings, but did not follow safe procedures in using the product.

3. Subject did not view warnings or instructions, but used the product safely.

4. Subject viewed instructions only and used the product in a safe manner.

5. Subject viewed instructions and warnings and used the product in a safe manner.

An attempt to fit a satisfactory discriminant function for the data showed that it was not possible to fit a func- tion for the five categories of behavior with satisfactory prediction accuracy. The five categories were then collapsed into the following two groups:

"Unsafe" Group: Original groups $1 \& 2$

"Safe" Group: Original groups 3,4, \& 5.

With this change, it was possible to predict the behavior of subjects with the following accuracies:
Electric knife: $68 \%$

Sabre-saw: 73\%

Drain cleaner: $79 \%$

Router: $86 \%$

The variables which proved to be most useful for predicting behavior for each product are shown below, with a comment following each about the nature of the relationship:

\section{Sabre-saw}

1. Score from questionnaire for measuring risk-taking attitude. Subjects with a higher score, i.e., less willing to take risks, were more likely to behave safely.

2. Score from the Zuckerman experience seeking scale. The more experience-seeking a subject claimed to be, the safer their behavior, which is the opposite of the expected result.

3. Crossing behavior at a pedestrian crossing. The behavior was as expected, i.e., subjects who didn't cross on a "Don't Walk" sign were more likely to behave safely.

Electric Knife

1. Score from questionnaire for measuring risk-taking attitude. Same comment as for sabre-saw.

2. Age of the subject. The lower the age, the more likely the subject was to behave safely.

3. Recency of use. The more recent the use of the knife, the safer the behavior.

Router

1. Score from questionnaire for measuring risk-taking attitude. Same comment as for the sabre-saw.

2 Age of the subject. The higher the age, the safer the behavior of the subject.

3. Familiarity with the product. The more familiar the subject with the router, the safer the behavior.

4. Seat belt usage in town. A subject using a seat belt in town was more likely to use the router safely.

5. Crossing behavior at pedestrian crossings. Same comment as for the sabre-saw. 


\section{Drain Cleaner}

1. Score from the questionnaire for measuring risk-taking attitude. Same comment as for the sabre-saw.

2. Score from the Zuckerman experienceseeking scale. Same comment as for. sabre-saw.

3. Subjective rating of the hazard of the product. The higher the subjective rating, the more likely the subject was the behave safely.

It was found that few of the subjects had any injury experience with the products, thus it is not surprising that this variable did not have any significant predictive value.

\section{CONCLUSIONS}

1. It is possible to measure risktaking attitude with a questionnaire which has significant value in predicting the safe or unsafe behavior of persons when asked to use a product.

2. Discriminant analysis is a useful tool for dealing with the experimental variables which must be studied as a group when performing this type of safety research

in a "real world" setting.

3. There is a need for much more research to help define the critical variables which determine whether someone will behave safely when confronted with a choice in using a variety of common products found around the household.

\section{REFERENCES}

Dorris, A. and Purswell, J., "Warnings and Human Behavior: Implications for the Design of Product Warnings", Journal of Products Liability, Vol. 1, 1977 .

Dorris, A. and Tabrizi, M. F., "Consumer Perception of Product Safety: An Empirical Evaluation", Journal of Products Liability, Vol. 2, 1978.

Godfrey, S. et al., "Warning Messages: Will the Consumer Bother to Look". Proceedings of the Human Factors Society 27th Annual Meeting, 1983.

Schwartz, D., et al.. "The Impact of Product Hazard Information on Consumer Buying Decisions: A Policy Capturing Approach", Proceedings of the Human Factors Society 22nd Annual meeting,
Slovic, P., et al., "Perceived Risk: Psychlogical Factors and Social

Implications", The Assessment and Perception of Risk, Royal Society of London, $198 \bar{\varnothing}$.

Wright, P. et al. "Some Factors Determining when Instructions will be Read", Ergonomics, Vol. 25, No. 3, 1982.

Zuckerman, M., "Interest and Preference Test", Sensation Seeking: Beyond the Optimal Level of $\overline{\text { Arousal, Halstea }}$ Press Division of Wiley, New York, 1979.

1978 . 